\section{Readmissions in elderly patients with heart failure. A retrospective study}

\author{
Rita Vieira Alves, Marília Fernandes, \\ Inês Figueiredo, \\ Diogo Drummond Borges, \\ Filipa Lourenço \\ Medicina 7.2, Hospital Curry Cabral, \\ Centro Hospitalar Lisboa Central \\ (CHLC), Lisboa, Portugal
}

\begin{abstract}
Heart failure is a major cause of morbidity and mortality worldwide. The prevalence increases with age and usually progresses, leading to repeated hospital admissions and significant symptom burden for patients. The correct management of these patients may decrease readmissions and increase quality of life.
\end{abstract}

Our aim is to compare elderly patients with and without 1-year readmissions in an internal medicine ward, particularly in terms of mortality.

Retrospective study, consulting patient's clinical records, with a diagnosis of heart failure. The patients were characterized and divided in groups: with (wR) and without readmission (woR) within 1 year. Mortality was the primary outcome.

Eighty-nine patients were included; 60 woR and 29 wR. There was no gender difference between groups, the wR group had older patients. The most frequent comorbidities included atrial fibrillation, hypertension and chronic renal failure stage 3 or higher. The most frequent cause of hospitalization was heart failure due to insufficient therapy or natural progression of the disease. The etiology of heart failure was mainly hypertensive and ischemic. The wR group had more patients classified as NYHA > III . In relation to the primary outcome; mortality at 12 months was higher in the group with repeated admissions .

The characterization of this population allows us to highlight the causes of decompensation and to review medication in order to increase the quality of life.

\section{Introduction and objectives}

Heart failure is defined as a clinical syndrome comprised of typical symptoms including breathlessness, fatigue and peripheral edema, among others, many related to congestion and fluid overload resulting from structural or functional cardiac abnormality. ${ }^{1-}$ ${ }^{5}$ Heart failure is currently divided in three subgroups; heart failure with decreased ejection fraction $(\mathrm{EF})(\mathrm{EF}<40 \%)$, heart failure with intermediate EF (EF 40-49\%) which currently has no clinical implications but is a target for research, and finally heart failure with preserved $\mathrm{EF}(\mathrm{EF}>50 \%) .{ }^{5}$ Heart failure severity is classified according to symptom severity and exercise tolerance using the New York Heart Academy functional classification.

Heart failure is a major cause of morbidity and mortality worldwide; it affects about $2 \%$ of the adult population, and the lifetime risk of developing heart failure is one in five. ${ }^{1-3}$ The prevalence increases with age and it is associated with highly prevalent comorbidities such as hypertension, coronary artery disease, cardiomyopathies and valve disease. As a result of ageing of the population the prevalence of heart failure is projected to increase by $25 \%$ in the next 20 years. ${ }^{1,3}$ Mortality remains high despite improvements, with a rate of $6-7 \%$ in chronic heart failure and $25 \%$ in patients with acute decompensations and hospital admission. . $^{1,36-}$ ${ }^{9}$ According to European guidelines, ${ }^{5}$ heart failure with reduced EF treatment is based on neuro-hormonal antagonists and devices to block the remodeling of the heart and improve outcomes and diuretics for relief of congestion. ${ }^{3,5}$ Neuro-hormonal antagonists include ACE inhibitors; angiotensin receptor blockers (ARBs); $\beta$ blockers; mineralocorticoid receptor antagonists (MRAs); and, based on more recent data, angiotensin receptor blocker neprilysin inhibitors (ARNIs). These interventions have been shown to improve outcomes. ${ }^{5}$

Heart failure has complex symptoms associated, with uncertain prognosis, with multiple hospital admissions to control episodes of decompensation. ${ }^{4}$ Heart failure usually progresses, and is many times, a fatal condition, which provides much symptom burden for patients.

\section{Materials and Methods}

We describe a retrospective study, consulting a patient's clinical records, hospital population over 65 years of age with a diagnosis of heart failure, hospitalized in the year of 2017, in an internal medicine ward in a tertiary hospital. Patients were in Lisbon. We divided the population into 2 groups with (wR) and without (woR) hospital readmission within 1 year and were compared regarding the patient's gender, age, level of autonomy, comorbidities and
Correspondence: Rita Vieira Alves, Rua Augusto Gil 23, 3o Dto, 1000-063, Lisboa , Portugal.

Tel.: +35.1924025088

E-mail: rita.vieira.alves@gmail.com

Key words: Readmissions; elderly care; heart failure; geriatrics.

Contributions: the authors contributed equally.

Conflict of interest: the authors declare no potential conflict of interest.

Ethics approval: the type of article did not use any data and the ethics committee was not necessary.

Further information: this study was present at the 18th European Congress of Internal

Medicine, in Lisbon, August 2019 as an oral presentation.

Received for publication: 13 May 2020.

Accepted for publication: 25 August 2020.

This work is licensed under a Creative

Commons Attribution-NonCommercial 4.0

International License (CC BY-NC 4.0).

${ }^{\circ}$ Copyright: the Author(s), 2020

Licensee PAGEPress, Italy

Geriatric Care 2020; 6:9106

doi:10.4081/gc.2020.9106

reason for hospitalization. The etiology of heart disease, BNP assay and echocardiogram were characterized. The primary outcome was death at 12 months.

\section{Results}

Eighty-nine patients were included; 60 woR and 29 wR (mean number of readmissions within a year was 2.6). There was no gender difference between groups $(38 \%$ woR / $37.9 \% \mathrm{wR})$, the wR group had older patients ( 77.28 years woR / $79.5 \mathrm{wR})$ with no difference in independence in activities of daily living ( $35 \%$ woR / $34.5 \% \mathrm{wR})$. The most frequent comorbidities included atrial fibrillation (46.6\% woR / 41.7\% wR), hypertension ( $41.3 \%$ woR / $40 \% \mathrm{wR})$, and chronic renal failure stage 3 or higher (28.3\% woR / 37.9\% wR). The most frequent cause of hospitalization was heart failure due to insufficient therapy or natural progression of the disease $(45 \%$ woR / $72.4 \% \mathrm{wR}$ ), or an infectious process as a decompensating factor of heart disease (16.6\% woR / $20.7 \%$ wR). The etiology of heart failure was mainly hypertensive $(51 \%$ 
woR / 41.4\% wR) and ischemic (21\% woR / 37.9\% wR). The wR group had more patients classified as NYHA > III $(16.6 \%$ woR / 31\% wR). 75 patients had an Echocardiogram, all with structural changes and $10 \%$ woR VS $48 \%$ wR had decreased ejection fraction (EF). No difference between groups in BNP quantification (941 woR / $807 w R) .57$ were taking beta-blockers, 52 were on angiotensin converting enzyme inhibitors or angiotensin receptor blockers and 69 patients were taking a diuretic at admission. None of the patients were on angiotensin receptor blocker neprilysin inhibitors (ARNIs). In relation to the primary outcome; mortality at 12 months was higher in the group with repeated admissions (16.6\% woR / 31.03\% wR).

\section{Conclusions}

Heart failure is a progressive disease, which causes repeated hospitalizations, especially in more advanced stages of the disease (as classified by NYHA), usually in patients with decreased EF, as was the case in our small sample. We found that this population was not optimally medicated according to European guidelines. We also found a higher mortality, in the group with readmissions which is also in line with what is described in the literature. The characterization of this population allows us to highlight the causes of decompensation and to review medication in order to decrease readmissions and increase the quality of life.

\section{References}

1. Bui AL, Horwich TB, Fonarow GC. Epidemiology and risk profile of heart failure. Nature Rev Cardiol 2010;8: 30-41.

2. Savarese G, Lund LH. Global public health burden of heart failure. Cardiac Failure Rev 2017;3:7-11.

3. Metra M, Teerlink JR. Heart failure. Lancet 2017;390:1981-95.
4. Beattie JM, Johnson MJ. Subcutaneous furosemide in advanced heart failure: Has clinical practice run ahead of the evidence base? BMJ Support Palliat Care 2012;2:5-6.

5. Ponikowski P, Voors AA, Anker SD, et al. 2016 ESC guidelines for the diagnosis and treatment of acute and chronic heart failure The task force for the diagnosis and treatment of acute and chronic heart failure of the European society of cardiology (ESC)developed with the special contribution of the heart failure association (HFA) of the ESC. Eur Heart J 2016;37:2129-200.

6. Pearse SG, Cowie MR. Heart failure: classification and pathophysiology. Medicine. 2014;42:556-61.

7. Haydock PM, Cowie MR. Heart failure: classification and pathophysiology. Medicine. 2010;38:467-72.

8. Chan M, Tsuyuki R. Heart failure in the elderly. Curr Opin Cardiol 2013;28: 234-41.

9. Maggioni AP. Epidemiology of heart failure in Europe. Heart Fail Clin 2015;11:625-35. 